V.2, N.1, 2018

DOI: $10.33947 / 2595-6264-v 2 n 1-3437$

\title{
QUANTITATIVO DE ÁGUAS CINZAS E NEGRAS EM BANHEIROS DE UM CENTRO UNIVERSITÁRIO EM MACEIÓ-ALAGOAS
}

\section{QUANTITATIVE OF ASH AND BLACK WATER IN THE BATHROOMS OF A UNIVERSITY CENTER IN MACEIÓ, ALAGOAS}

José Wanderson de Andrade Fernandes ${ }^{1}$, Renato Américo Araujo Neto², Joelmir José Albuquerque Farias ${ }^{3}$, Ranieri Carlos Ferreira Amorim ${ }^{4}$

RESUMO: O aumento da população mundial ocasionou um maior consumo de água, aumentando o desperdício desta, sendo necessário adotar medidas de economia de água, como o reuso. Portanto, objetivou-se estimar o consumo de águas cinzas e negras em banheiros de uma Instituição de Ensino Superior - IES em Maceió, Alagoas. O estudo consistiu de uma coleta de dados de vazão dos vasos sanitários e torneiras dos banheiros da IES. Para contabilizar a quantidade de água desperdiçada, utilizou-se a quantidade de discentes na instituição, em relação aos cursos existentes. Com os dados, procedeu-se a estimativa da quantidade de águas cinzas e negras desperdiçadas na IES, através da seguinte forma: consumo real, através da quantidade de discentes e consumo máximo, supondo que todas as salas de aula estarão na capacidade máxima de discentes. Observou-se que o desperdício máximo da instituição é de 5,7 milhões de litros por ano para águas cinzas e 39 milhões de litros por ano para águas negras. Com esses resultados, há a necessidade de realizar estudos futuros em relação ao reuso de águas cinzas e negras na IES, podendo calcular o valor econômico para o reuso destas águas.

PALAVRAS-CHAVE: Águas residuais. Estimativa de Consumo. Desperdício de água.

ABSTRACT: The increase of the world population caused a greater consumption of water, increasing the waste of this one, being necessary to adopt measures of saving of water, like the reuse. Therefore, it was aimed to estimate the gray and black water consumption in bathrooms of a Higher Education Institution - HEI in Maceió, Alagoas. The study consisted of a data collection of flow of the toilets and taps of the bathrooms of the HEl. In order to account for wasted water, the number of students in the institution was used in relation to the existing courses. With the data, it was estimated the amount of ash and black water wasted in the HEl, using the following form: real consumption, through the number of students and maximum consumption, assuming that all classrooms will be in the maximum capacity of students. It was observed that the maximum waste of the institution is 5.7 million liters per year for gray water and 39 million liters per year for black water. With these results, it is necessary to carry out future studies in relation to the reuse of gray and black water in the HEl, and can calculate the economic value for the reuse of these waters.

KEYWORDS: Residual waters. Estimation of Consumption. Waste Water. 
QUANTITATIVO DE ÁGUAS CINZAS E NEGRAS EM BANHEIROS DE UM CENTRO UNIVERSITÁRIO EM MACEIÓ-ALAGOAS José Wanderson de Andrade Fernandes, Renato Américo Araujo Neto, Joelmir José Albuquerque Farias, Ranieri Carlos Ferreira Amorim

\section{V.2, N.1, 2018}

\section{INTRODUÇÃO}

A água é um recurso essencial para a manutenção e desenvolvimento da vida, estando inserida desde a composição das nossas células, até nos procedimentos industriais e agrícolas mais complexos. O Relatório das Nações Unidas sobre o Desenvolvimento de Água garante que, se medidas não forem tomadas, até 2030 o planeta enfrentará um déficit de água de 40\% (UNESCO, 2015). Atualmente, o ramo da Engenharia Civil pode contribuir significativamente na busca de soluções as quais sejam sustentáveis, econômicas e eficazes podendo assim solucionar diversos tipos de problemas, gerando uma economia e reuso de água em diversos ambientes, seja residencial, industrial ou profissional.

Uma das metodologias que contribuem com a sustentabilidade, está no reuso de águas cinzas e negras. A distinção básica entre esses dois tipos de águas é descrita quanto à sua utilização. As águas cinzas são provenientes de processos domésticos, como lavatórios, chuveiros e máquinas de lavar roupas e louças, enquanto as águas negras são aquelas provenientes de urina e fezes. O sistema de reuso é contundentemente utilizado; garantindo a possibilidade de usar água de lavatório, ou bacia sanitária, para outras atividades de uso não potável como por exemplo na irrigação, descargas, etc. O principal objetivo do sistema de reuso é evitar o consumo de água potável em procedimentos em que seu uso é totalmente dispensável, podendo ser substituída, gerando vantagens econômicas nos diversos setores (Hespanhol, 2003). Vários locais utilizam sistemas de reutilização de águas cinzas e negras. A Namíbia por exemplo, que possui um clima desértico, consequentemente com escassez de água, optou pelo sistema de reuso por uma questão de necessidade e sobrevivência e por uma melhor relação custo-benefício, já que importar água tornava-se mais oneroso que a água de reuso (Fiori et al., 2006; Castilho e Oliveira, 2018).

Quanto ao uso domiciliar e empresas, o reuso de águas cinzas e negras, tem influência de diversos fatores entre eles causando economia no consumo de água potável. No entanto, para que seja realizada uma proposta de consumo dessas águas de reuso, o número de habitantes é o fator que mais influência na demanda e contabilidade de água a ser consumida. Carvalho et al. (2014) em seu estudo, enfatiza a necessidade de pesquisas que discutam a implementação do uso racional de água. Embora diversas campanhas de educação e incentivo para o uso consciente e correto da água sejam implantadas e incentivadas constantemente pelas companhias sanitárias, ainda é constante as negligências no uso da água em zonas urbanas. Os desperdícios são muitos, tanto em uso industrial quanto doméstico. Todavia, com o avanço das tecnologias e pesquisas científicas, a reutilização vem sendo uma forma de amenizar o desperdício lançando mão de técnicas e equipamentos para que as águas residuais atinjam padrão de qualidade mínimo para serem reaproveitadas de acordo com a atividade em que ela será utilizada.

Diante do exposto, o estudo teve como objetivo estimar o consumo de água em banheiros de uma Instituição de ensino Superior em Maceió - Alagoas, estimando águas cinzas e negras pelo quantitativo de discentes na instituição.

\section{MATERIAL E MÉTODOS}

O estudo foi conduzido com pesquisa de um conjunto de dados em uma Instituição de Ensino Superior (IES), localizado em Maceió, Alagoas. A instituição possui 9 pavimentos, sendo objeto de estudo os pavimentos que contém as salas de aulas. A coleta dos dados consistiu em uma pesquisa do quantitativo de alunos que frequentam a IES, através de entrevistas com os coordenadores dos cursos existentes. Também foi gerado um quantitativo dos totais de salas de aula e banheiro na IES. Com isso, uma série de dados foram gerados, como mostra a Tabela 1.

Tabela 1. Quantitativo dos parâmetros essenciais para o cálculo da quantidade de água desperdiçada.

\begin{tabular}{lc}
\hline Descrição & Quantidade \\
\hline Sala de aula & 70 \\
Banheiros & 16 \\
Vasos Sanitários & 90 \\
Torneiras & 54 \\
\hline
\end{tabular}

Foram ainda coletadas as vazões de água das torneiras e descargas dos vasos sanitários, seguindo as normas da NBR 5626 (1998), apresentando as seguintes vazões: Válvula de descarga (1,70 litros por segundo - $\mathrm{L}$ $\left.\mathrm{s}^{-1}\right)$; torneira da pia $\left(0,25 \mathrm{~L} \mathrm{~s}^{-1}\right)$. O tempo de funcionamento de cada válvula, tanto da descarga, como da pia foi de 5 segundos, com utilização delas estimada em 3 vezes por pessoa. Com isso, temos a vazão desses equipamentos por dia e por pessoa, como segue a equação: 
QUANTITATIVO DE ÁGUAS CINZAS E NEGRAS EM BANHEIROS DE UM CENTRO UNIVERSITÁRIO EM MACEIÓ-ALAGOAS José Wanderson de Andrade Fernandes, Renato Américo Araujo Neto, Joelmir José Albuquerque Farias, Ranieri Carlos Ferreira Amorim

\section{V.2, N.1, 2018}

Vazão (litros pessoa dia $\left.{ }^{-1}\right)=$ vazão do material $\left(I s^{-1}\right) \times$ tempo(s) $\times$ vezes de utilização

(1)

Foram descritos ainda os seguintes parâmetros: 1 . Quantidade de águas cinzas e negras geradas por discente; 2. Quantidade de águas cinzas e negras, supondo que há a capacidade máxima das salas de aula na IES. Para cada um desses parâmetros, estimou-se a quantidade total dessas águas por dia $\left(\mathrm{L} \mathrm{dia}^{-1}\right)$ e anualmente, supondo a utilização da IES todos os dias do ano $\left(\mathrm{L} \mathrm{dia}^{-1} \mathrm{ano}^{-1}\right)$.

\section{RESULTADOS E DISCUSSÃO}

O total de discentes na instituição e o quantitativo de águas cinzas e negras é descrito na Tabela 2. Já o quantitativo de águas cinzas e negras na capacidade máxima da IES é descrito na Tabela 3.

Tabela 2. Quantitativo da utilização de águas cinzas e negras por discentes em uma IES em Maceió, Alagoas.

\begin{tabular}{ccc}
\hline $\begin{array}{c}\text { Discentes (total } \\
\text { de } 3461)\end{array}$ & Águas cinzas & Águas negras \\
\hline Total $\left(\mathrm{L} \mathrm{dia}^{-1}\right)$ & $12.978,75$ & $88.255,50$ \\
Total $\left(\mathrm{L} \mathrm{ano}^{-1}\right)$ & $4.737 .243,75$ & $32.213 .257,50$ \\
\hline
\end{tabular}

A Tabela 2 apresenta um total de aproximadamente 4,7 milhões de litros de águas cinzas por ano. Esse quantitativo representa $12 \%$ do total de água que é desperdiçada através do uso dos banheiros na IES. O total de águas cinzas por aluno é de $1.368,75 \mathrm{~L}_{\text {ano }}{ }^{-1}$. Por dia, cada discente utiliza 25,5 litros de águas negras, representando $87 \%$ do consumo total de águas cinzas e negras. O estudo apresenta um grande potencial para aplicabilidade do uso de águas residuárias em outras vertentes dentre da IES. Observa-se que se houver a reutilização tanto de águas cinzas, como negras a IES terá um aproveitamento de aproximadamente $90 \%$ de água, diminuindo os custos e gerando um potencial de reaproveitamento. Para isto, é necessário um estudo econômico, visando a diminuição dos gastos financeiros.

Estudos realizados por Melo (2016) mostram a eficácia na contabilidade de águas provenientes de diversos locais. $\mathrm{O}$ autor ainda propõe um estudo de custo financeiro em seu local de estudo, mostrando a importância tanto do gasto de águas cinzas e negras, quanto o co- nhecimento desse quantitativo, visando uma economia financeira para o local de estudo. Esse procedimento também seria essencial na contabilidade de custos no gasto de água na instituição. Além de um estudo econômico, um estudo técnico deve ser realizado, enfatizando a implantação de sistemas de esgotamento específico para águas cinzas e negras (Fiori et al., 2006).

Tabela 3. Quantitativo máximo de águas cinzas e negras em uma IES em Maceió, Alagoas.

\begin{tabular}{|c|c|c|}
\hline $\begin{array}{c}\text { Discentes } \\
\text { (capacidade } \\
\text { total) }\end{array}$ & Águas cinzas & Águas negras \\
\hline Total $\left(\mathrm{L} \mathrm{dia}^{-1}\right)$ & $15.750,00$ & $107.100,00$ \\
\hline Total $\left(\mathrm{L}\right.$ dia $^{-1}$ ano $\left.^{-1}\right)$ & $5.748 .750,00$ & $39.091 .500,00$ \\
\hline
\end{tabular}

A quantidade de água desperdiçada $\left(\mathrm{L} \mathrm{dia}^{-1}\right)$ por curso na IES é apresentada na Figura 1. Observa-se que há uma disparidade do uso dos banheiros do curso $D$ em relação aos demais. Vê-se que o desperdício de águas cinzas e negras acompanham o quantitativo dos discentes que frequentam a IES. Em geral, a relação entre o uso de válvula de descarga e torneiras de pias é de 6,8 , ou seja, há um maior consumo de águas negras em relação às águas cinzas. Esse fato é ocasionado devido a uma maior vazão da válvula de descarga.

Figura 1. Relação entre o consumo de águas cinzas e águas negras com o quantitativo de discentes na IES.

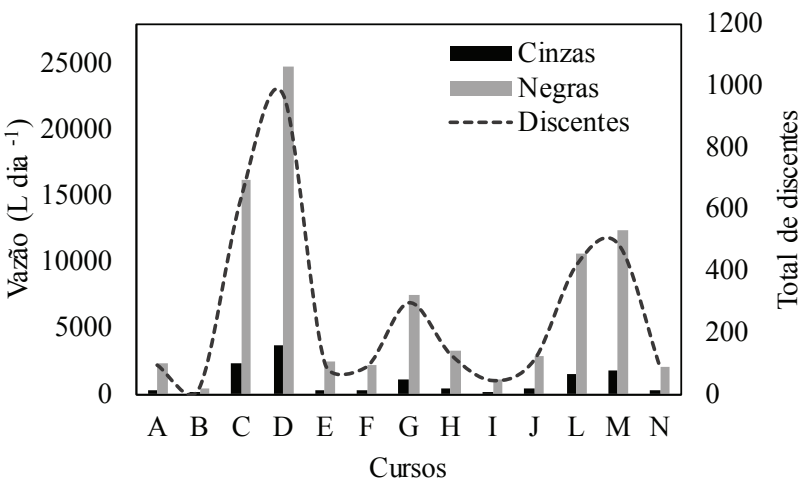

A tabela 3 apresenta o consumo total de águas cinzas e negras, supondo que todas as salas de aula da IES estejam preenchidas com os discentes (total de 60 discentes por sala). Os valores de águas cinzas e negras foram aproximadamente 5,7 milhões e 39 milhões de litros desperdiçados em um ano. Relacionando com a quantidade real de discentes, observa-se este corresponde a $82 \%$ do 
V.2, N.1, 2018

total da IES (Tabela 2; Tabela 3). Uma alternativa para diminuição do gasto de águas cinzas e negras é gerar pesquisas que envolvam o uso consciente de água, implantando metodologias que reutilizem as águas cinzas e negras em sistemas de irrigação, ou mesmo o retorno destas para uso em vasos sanitários (Carvalho et al., 2014; Melo, 2016; Fernandes, 2018). Com isso, o reuso das águas cinzas e negras amenizará o desperdício de água e gerará economia de água na IES.

\section{CONCLUSÃO}

$\mathrm{Na}$ estimativa do gasto de água proveniente dos banheiros da IES, tem-se que há um consumo de $82 \%$ de águas cinzas e negras do limite máximo da IES. Observa-se ainda que um consumo sustentável pode ser adotado, utilizando-se técnicas que forneçam o reaproveitamento dessas águas em outros ambientes na IES. Com os dados disponíveis, abre-se um leque para estudos econômicos sobre o reuso de águas na IES. Com isso, será possível avaliar a possibilidade do reuso de águas cinzas e negras, podendo propiciar uma economia considerável na instituição.

\section{REFERÊNCIAS}

ABNT, ASSOCIAÇÃO BRASILEIRA DE NORMAS TECNICAS. Instalação predial de água fria. Rio de Janeiro, 1998. $41 \mathrm{p}$.

CARVALHO, N. L. C.; HENTZ, P.; SILVA, J. M.; BARCELLOS, A. L. Revista Monografias Ambientais - REMOA, v. 14, n. 2, p. 3164-3171, Mar. 2014.

CASTILHO, C. P.; OLIVEIRA, L. H. Avaliação durante operação de sistemas de água não potável em edifícios residenciais. Ambiente Construído, Porto Alegre, v. 18, n. 1, p. 409-421, jan./mar. 2018.

FERNANDES, J. W. A. Consumo de águas cinzas e negras nos banheiros do centro universitário UNINASSAU. 2018. 38 f. Trabalho de Conclusão de Curso. (Graduação em Engenharia Civil) - UNINASSAU, Maceió, 2018.

FIORI, S.; FERNANDES, V. M. C.; PIZZO, H. Ambiente construído, Porto Alegre, v. 6, n. 1, p. 19-30, jan./mar. 2006.

HESPANHOL, I. Potencial de reuso de água no Brasil: agricultura, indústria, municípios, recarga de aquíferos. Rev. Bras. Recur. Hídricos. v. 7, n. 4, p. 75-95, 2002.

MELO, H. D. A. Estudo técnico sobre a viabilidade econômica do reuso das águas residuais em um condomínio fechado. 2016. $62 \mathrm{f}$. Trabalho de Conclusão de Curso. (Graduação em Engenharia Civil) - UNINASSAU, Maceió, 2016.

UNESCO. Relatório mundial das Nações Unidas sobre desenvolvimento recursos. Itália, 2015. 8 p. 